\title{
Comparison of drug delivery from conventional versus "Venturi" nebulizers
}

\author{
S.G. Devadason, M.L. Everard, J.M. Linto, P.N. Le Souëf
}

\begin{abstract}
Comparison of drug delivery from conventional versus "Venturi" nebulizers. S.G. Devadason, M.L. Everard, J.M. Linto, P.N. Le Souëf. (C)ERS Journals Ltd 1997.

ABSTRACT: Attempts to improve drug delivery from conventional jet nebulizers have included the use of storage systems to reduce drug wastage during exhalation. Venturi nebulizers enhance drug delivery during inhalation, reducing treatment times and drug wastage. This study investigated the effect of age on inhaled dose from a conventional jet nebulizer $(A \operatorname{corn} 囚)$ used both with and without a storage chamber (Mizer $\left.{ }^{\circledR}\right)$, compared to two Venturi nebulizers (Ventstream ${ }^{\circledR}$ and Pari LC@).

Filters were attached to the four nebulizer systems, containing salbutamol, and 18 children with cystic fibrosis (3-16 yrs) inhaled through these devices. The quantity of drug collected on the filter was assessed using ultraviolet spectrophotometry. The particle size distribution of the aerosol from each nebulizer system was measured using laser diffraction.

Inspiratory filter deposition using the Acorn ${ }^{\circledR}$ was lower than the Acorn ${ }^{\circledR}$ with Mizer ${ }^{\circledR}$, and both Venturi nebulizers. Filter deposition using the Acorn ${ }^{\circledR}$ with Mizer ${ }^{\circledR}$ was lower than the Pari LC@. No trend with age, height or weight was noted using any nebulizer. Aerosol particle size using the Ventstream ${ }^{\circledR}$ was lower than the other nebulizer systems.

Drug output from both Venturi nebulizers was more efficient than from the jet nebulizer, used with and without the storage chamber, during inhalation by children with cystic fibrosis. The inhaled dose did not change with the patient's age or size using both types of nebulizer.

Eur Respir J 1997; 10: 2479-2483.
\end{abstract}

Dept of Respiratory Medicine, Princess Margaret Hospital for Children and Dept of Paediatrics, University of Western Australia, Australia.

Correspondence: S.G. Devadason Dept of Respiratory Medicine

Princess Margaret Hospital for Children

Roberts Road

Subiaco 6008

Western Australia

Keywords: Aerosol therapy

drug delivery

inhalation systems

nebulizer output

Received: October 211996

Accepted after revision July 11997

Partial sponsorship by Pari (Germany) and MedicAid (UK).
Jet nebulizers have been used for many years to treat asthma and other respiratory diseases. However, they remain a relatively inefficient form of drug delivery with considerable variation in the performance characteristics of the different jet nebulizer systems available [1]. Drug delivery to the lungs with these devices is generally less than $10 \%$ of the prescribed dose [2-6]. There are a number of reasons for this inefficient drug delivery which include large "dead volumes" [1] and wastage of aerosol generated during the noninspiratory portion of the respiratory cycle $[7,8]$. A number of strategies have been used in an attempt to overcome the latter problem. These have included incorporating a manual interrupter which permits the patient to divert the driving gas flow away from the nebulizer during exhalation so that aerosol is only generated while the patient is inhaling [9-11]. An alternative strategy has been to store the aerosol, generated while the patient is exhaling, either in wide bore tubing connected to the exhalation port of the nebulizer or in storage chambers such as the Mizer@ (MedicAid, Pagham, UK) [3, 12, 13]. Neither of these approaches have found widespread acceptance. The former significantly increases nebulization times and hence is more inconvenient for patients. Storage chambers have not been widely used, except for the administration of expensive drugs such as antibio- tics, despite evidence that they do enhance drug delivery $[3,12,13]$.

Entraining air through the nebulizer as the patient inhales has been known for some time to increase the output of drug without significantly affecting the particle size distribution of the aerosol [14, 15]. Recently a number of so-called Venturi nebulizers, based on this principle, have been designed in order to improve drug delivery without creating a system that is more inconvenient to use than a standard jet nebulizer $[10,11,15$, 16]. As with conventional jet nebulizers, Venturi nebulizers generate a continuous output of aerosol, the rate of generation being determined by the design of the nebulizer and the driving gas flow used. As patients inhale from the device, air is entrained through the nebulizer bowl resulting in increased output of aerosol. This is said to be due to drying of droplets prior to impaction on the baffle [15]. Consequently, the proportion of aerosol generated during inspiration is considerably greater than during exhalation and hence the proportion lost directly to the atmosphere as the patient exhales is reduced.

Previous work has suggested the absolute dose inhaled from a standard jet nebulizer is essentially constant from early childhood through to adulthood [6-8], although in practice there is considerable intrasubject 
variation due to factors other than those associated with an age effect. It is likely that storage chambers and Venturi nebulizers could be used to improve drug delivery to paediatric patients. A study was therefore undertaken in order to determine whether these devices enhance the inhaled dose when used by children compared to the dose delivered by a standard jet nebulizer.

\section{Materials and methods}

\section{Study subjects}

Eighteen patients with cystic fibrosis, aged 3-16 yrs, were recruited to the study. Those patients who were able to perform reliable spirometric manoeuvres had normal lung function (forced expiratory volume in one second $(\mathrm{FEV} 1)>80 \%$ predicted) at the time of the study (table 1). Approval for this study was granted by the Ethics Committee of Princess Margaret Hospital for Children. Informed consent was obtained from the parents and, where possible, the children.

\section{Study design}

Subjects attended the department on one occasion and inhaled in random order from four nebulizer systems: 1) the Acorn ${ }^{\circledR}$ (system 22); 2) the Acorn ${ }^{\circledR}$ and Mizer®; and 3) the Ventstream ${ }^{\circledR}$ (all MedicAid, Pagham, UK); and 4) the Pari LC® nebulizer (Pari, Starnberg, Germany) (fig. 1). Filter deposition was used to measure the amount of drug which would normally be inhaled by the subject.

\section{Methods}

The driving gas flow for the Acorn $®$, the Acorn ${ }^{\circledR}$ with Mizer ${ }^{\circledR}$ and the Ventstream ${ }^{\circledR}$ was $6.0 \mathrm{~L} \cdot \mathrm{min}^{-1}$ using the hospital compressed air supply. Flow was measured using an appropriately calibrated flow meter (Commonwealth Industrial Gases Ltd, Chatswood, NSW, Australia). The Pari LC® was used with the Pari Inhalierboy ${ }^{\circledR}$ compressor (flow $3.5 \mathrm{~L} \cdot \mathrm{min}^{-1}$ ). The nebulizers were filled with $2.5 \mathrm{~mL}$ of salbutamol sulphate $(1.0$ $\mathrm{mg} \cdot \mathrm{mL}^{-1}$; Ventolin nebules; Glaxo Wellcome Australia Ltd, Boronia, Victoria, Australia). Nebulization was continued until no further output was noted for $20 \mathrm{~s}$. Nebulizers were held still and not shaken or tapped. Low-resistance inspiratory filters (Kendall Curity anaesthesia filters, Mansfield, MA, USA) were attached to each nebulizer to trap the salbutamol that would have been inhaled by the patient. The filters and filter holders were subsequently washed in methanol and the quantity of salbutamol deposited was assayed using an ultraviolet spectrophotometric method $(\lambda=246 \mathrm{~nm})$. The quantity of drug remaining in the nebulizer chamber was also assayed.

Recovery of a known amount of salbutamol from filters which were washed and assayed using this method was $98.2 \%$ (SD 4.9; $n=6$ ). An Acorn ${ }^{\circledR}$ nebulizer, filled with the contents of a Ventolin nebule $(2.5 \mathrm{~mL}$ salbutamol; $1.0 \mathrm{mg} \cdot \mathrm{mL}^{-1}$ ) and fitted with filters at both ends of the T-piece, was allowed to nebulize to dryness. The recovery of salbutamol from this system (after washing the nebulizer and both filters) was $101.0 \%$ (SD 2.2; $\mathrm{n}=5$ ).

The particle size distribution of the output from each nebulizer was assessed using a Malvern Mastersizer X laser particle sizer (Malvern Instruments Ltd, Malvern, UK). Five measurements were performed for each type of nebulizer.

\section{Data analysis}

Filter deposition using the four nebulizer systems was calculated as the mean (SD) proportion (\%) of the nominal dose. Significant differences between devices in drug

Table 1. - Demographic details of the children recruited for the study

\begin{tabular}{|c|c|c|c|c|c|c|c|c|}
\hline \multirow{2}{*}{$\begin{array}{c}\text { Subject } \\
\text { No. }\end{array}$} & \multirow{2}{*}{$\begin{array}{l}\text { Age } \\
\text { yrs }\end{array}$} & \multirow[t]{2}{*}{ Gender } & \multirow{2}{*}{$\begin{array}{c}\text { Height } \\
\mathrm{cm}\end{array}$} & \multirow{2}{*}{$\begin{array}{c}\text { Weight } \\
\mathrm{kg}\end{array}$} & \multicolumn{2}{|c|}{ FVC } & \multicolumn{2}{|c|}{ FEV1 } \\
\hline & & & & & $\mathrm{L}$ & $\%$ pred & $\mathrm{L}$ & $\%$ pred \\
\hline 1 & 3 & $\mathrm{M}$ & 106 & 18 & - & - & - & - \\
\hline 2 & 4 & $\mathrm{~F}$ & 103 & 16 & - & - & - & - \\
\hline 3 & 4 & M & 106 & 18 & - & - & - & - \\
\hline 4 & 5 & M & 98 & 14 & 0.81 & 99 & 0.73 & 104 \\
\hline 5 & 5 & $\mathrm{~F}$ & 111 & 24 & 1.53 & 134 & 1.27 & 130 \\
\hline 6 & 6 & $\mathrm{M}$ & 119 & 22 & 1.31 & 89 & 1.13 & 89 \\
\hline 7 & 6 & $\mathrm{~F}$ & 115 & 19 & 1.33 & 106 & 0.98 & 90 \\
\hline 8 & 7 & $\mathrm{~F}$ & 124 & 23 & - & - & - & - \\
\hline 9 & 8 & F & 130 & 32 & 2.20 & 118 & 1.87 & 115 \\
\hline 10 & 9 & M & 131 & 29 & 2.65 & 130 & 1.77 & 98 \\
\hline 11 & 10 & M & 141 & 38 & 2.63 & 109 & 2.27 & 108 \\
\hline 12 & 10 & $\mathrm{~F}$ & 134 & 27 & 1.80 & 90 & 1.47 & 83 \\
\hline 13 & 10 & F & 139 & 33 & 1.92 & 88 & 1.55 & 80 \\
\hline 14 & 11 & $\mathrm{M}$ & 146 & 37 & 3.07 & 116 & 2.61 & 114 \\
\hline 15 & 12 & $\mathrm{~F}$ & 148 & 40 & 2.57 & 100 & 2.19 & 96 \\
\hline 16 & 13 & M & 148 & 37 & 2.59 & 94 & 2.24 & 95 \\
\hline 17 & 15 & F & 165 & 81 & 3.60 & 100 & 3.36 & 104 \\
\hline 18 & 16 & M & 173 & 49 & 4.39 & 98 & 3.11 & 81 \\
\hline
\end{tabular}

M: male; F: female; FVC: forced vital capacity; \% pred: percentage of predicted values; FEV1: forced expiratory volume in one second. 
a)

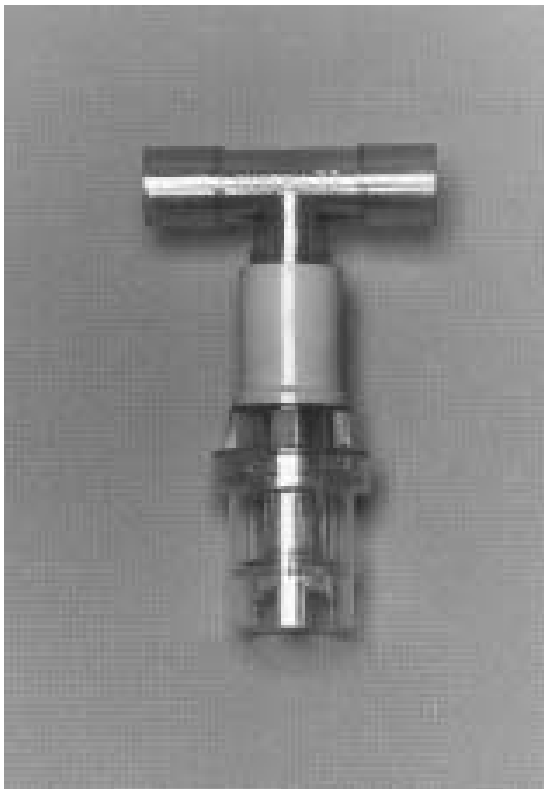

c)

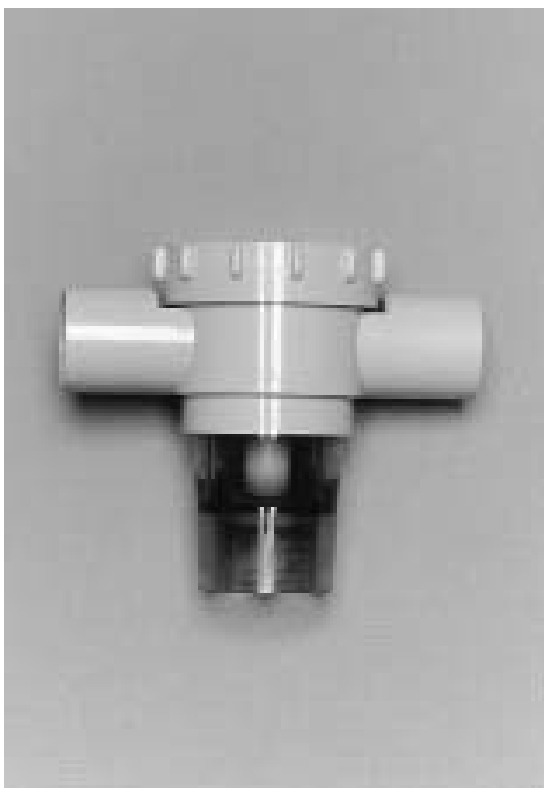

b)

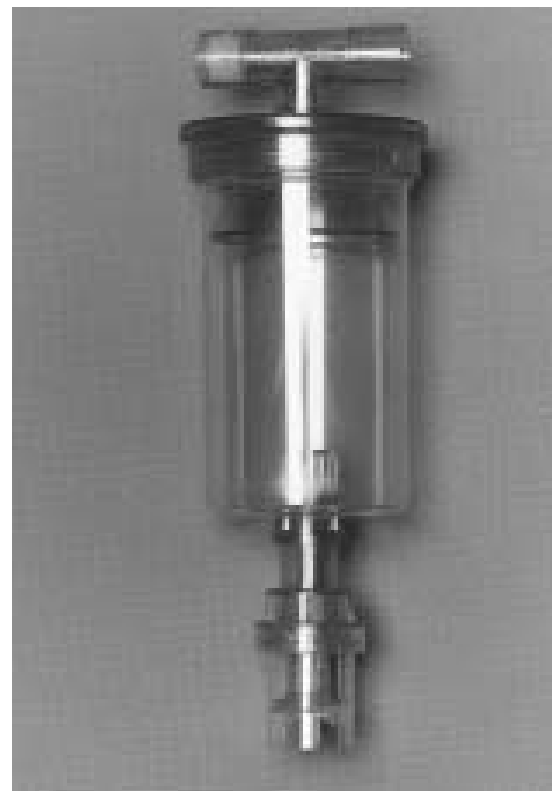

d)

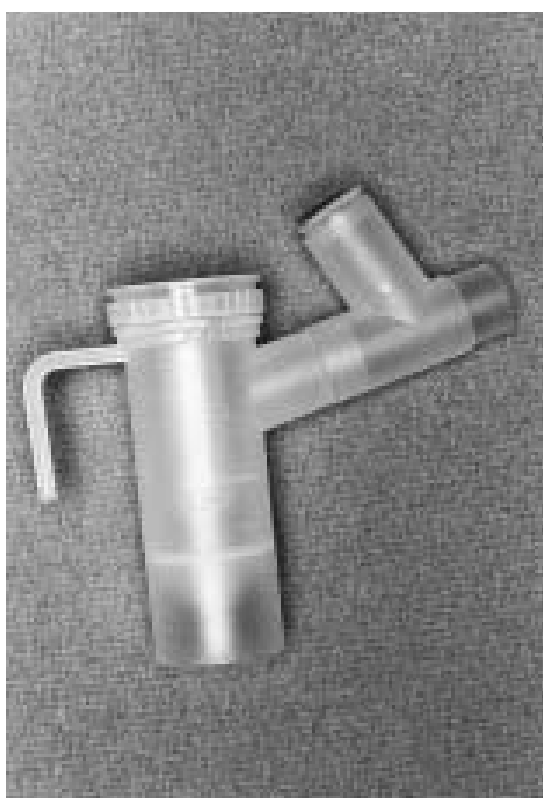

Fig. 1. - Devices tested include: a) the Acorn ${ }^{\circledR}$ (MedicAid, Pagham, UK), a disposable T-piece jet nebulizer, used alone; and b) with a Mizer ${ }^{\circledR}$ storage chamber (MedicAid); and two Venturi nebulizers: c) the Ventstream ${ }^{\circledR}$ (MedicAid); and d) the Pari LC® (Pari, Starnberg, Germany).

delivery, drug retained in the nebulizer bowl, and nebulization times were tested using analysis of variance (ANOVA) for repeated measurements. Post-hoc analysis was performed using the Fisher protected least significant difference (Fisher PLSD) with a significance level of $95 \%(\mathrm{p}<0.05)$, unless otherwise stated. Regression analyses were used to assess the effect of the subject's age, height and weight on drug delivery to inspiratory filters.

\section{Results}

The mass median aerodynamic diameters (MMADs) produced by the nebulizers used in this study at a flow of $6.0 \mathrm{~L} \cdot \mathrm{min}^{-1}$ were: Acorn ${ }^{\circledR} 5.56(\mathrm{SD} 0.21) \mu \mathrm{m}(\mathrm{span}$ 1.91 (SD 0.05)); Acorn ${ }^{\circledR} /$ Mizer ${ }^{\circledR} 6.19$ (SD 0.13) $\mu \mathrm{m}$ (span 1.78 (SD 0.06)); Ventstream ${ }^{\circledR} 3.57$ (SD 0.07) $\mu \mathrm{m}$ (span 1.44 (SD 0.03)); and Pari LC® 5.50 (SD 0.17) $\mu \mathrm{m}$ (span 1.74 (SD 0.06)) (fig. 2). The MMAD of the Ventstream ${ }^{\circledR}$ at $6.0 \mathrm{~L} \cdot \mathrm{min}^{-1}$ was significantly lower than that of the other nebulizers. When the Pari ${ }^{\circledR}$ was run using the Inhalierboy pump, the MMAD was 6.56 (SD $0.11) \mu \mathrm{m}$ (span 1.71 (SD 0.02)), which was significantly higher than the nebulizers run at $6.0 \mathrm{~L} \cdot \mathrm{min}^{-1}$.

The delivery of salbutamol to the inspiratory filters for each nebulizer is shown in table 2. There was no relationship between the age, height or weight of the subject and delivery of drug to the inspiratory filters. Similarly, the order in which the nebulizers were tested did not appear to affect the drug delivery to the inspiratory filters. The delivery of salbutamol to the inspiratory filters using the Acorn ${ }^{\circledR}$ was lower than the deposition from the Acorn ${ }^{\circledR}$ with Mizer ${ }^{\circledR}(\mathrm{p}<0.05)$ and 


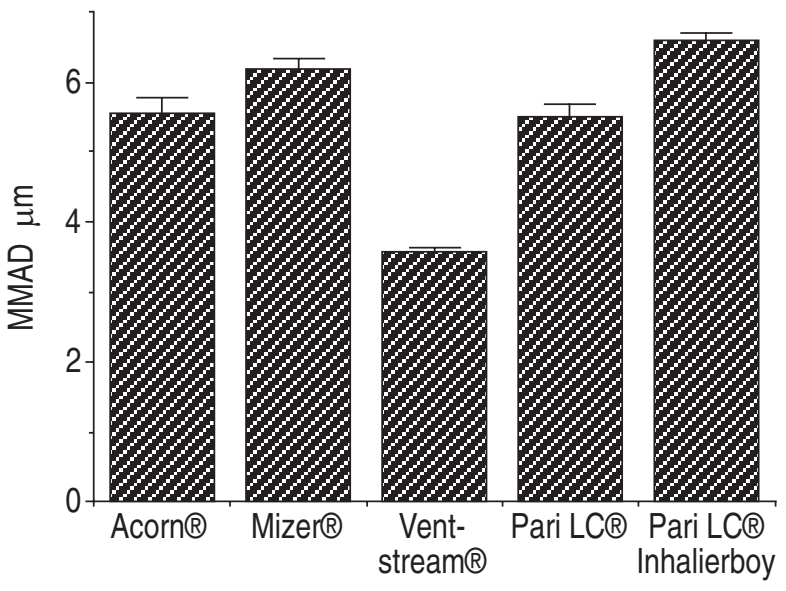

Fig. 2. - The mean (SD) of five measurements of the mass median aerodynamic diameter (MMAD) generated by the four nebulizer systems, operated with a driving gas flow of $6 \mathrm{~L} \cdot \mathrm{min}^{-1}$. The MMAD of the Pari LC® using the Inhalierboy pump was compared to that at 6 $\mathrm{L} \cdot \mathrm{min}^{-1}$.

Table 2. - Results of a filter study comparing the output (\% of nominal dose) of the Pari LC $₫$ and Ventstream $®$ nebulizers to the Acorn $\AA$, both with and without the Mizer®. Each nebulizer was filled with $2.5 \mathrm{~mL}$ of salbutamol $\left(1.0 \mathrm{mg} \cdot \mathrm{mL}^{-1}\right)$

\begin{tabular}{rrrcc}
\hline $\begin{array}{c}\text { Subject } \\
\text { No. }\end{array}$ & $\begin{array}{c}\text { Acorn }{ }^{\circledR} \\
6 \text { L } \cdot \mathrm{min}^{-1}\end{array}$ & $\begin{array}{c}\text { Mizer } \\
\text { 6 L } \cdot \mathrm{min}^{-1}\end{array}$ & $\begin{array}{c}\text { Ventstream } \\
\text { 6 L } \cdot \mathrm{min}^{-1}\end{array}$ & $\begin{array}{c}\text { PariLC® with } \\
\text { Inhalierboy }\end{array}$ \\
\hline 1 & 13.84 & 14.58 & 22.00 & 24.96 \\
2 & 9.04 & 13.20 & 16.42 & 19.96 \\
3 & 3.13 & 4.26 & 7.17 & 11.65 \\
4 & 5.66 & 6.88 & 21.64 & 13.14 \\
5 & 6.02 & 16.75 & 8.88 & 20.98 \\
6 & 7.63 & 20.16 & 12.08 & 10.71 \\
7 & 11.09 & 12.29 & 18.01 & 17.73 \\
8 & 10.75 & 6.59 & 21.19 & 24.50 \\
9 & 10.82 & 11.98 & 15.90 & 19.27 \\
10 & 13.06 & 16.74 & 24.41 & 18.75 \\
11 & 7.57 & 13.96 & 7.44 & 16.16 \\
12 & 8.88 & 12.20 & 28.56 & 22.25 \\
13 & 8.93 & 18.62 & 14.41 & 18.68 \\
14 & 8.10 & 14.35 & 19.41 & 21.44 \\
15 & 9.24 & 22.94 & 17.09 & 9.75 \\
16 & 10.75 & 17.16 & 28.53 & 14.41 \\
17 & 12.32 & 21.38 & 6.66 & 27.05 \\
18 & 11.50 & 5.33 & 19.75 & 30.92 \\
\hline Mean & 9.35 & 13.85 & 17.20 & 19.02 \\
SD & 2.74 & 5.45 & 6.83 & 5.78 \\
\hline
\end{tabular}

from both the Pari ${ }^{\circledR}$ and Ventstream ${ }^{\circledR}$ nebulizers $(\mathrm{p}<0.01)$ (fig. 3). The filter deposition using the Acorn ${ }^{\circledR}$ with Mizer ${ }^{\circledR}$ was lower than that using the Pari ${ }^{\circledR}$ nebulizer $(\mathrm{p}<0.01)$.

The time taken for cessation of output from each type of nebulizer was 10.8 (SD 3.2) min for the Acorn $\AA$, 10.2 (SD 2.3) min for the Acorn ${ }^{\circledR}$ and Mizer®, 11.8 (SD 3.0) min for the Ventstream ${ }^{\circledR}$ and 10.0 (SD 2.2) min for the Pari ${ }^{\circledR}$. There was no significant difference in total nebulization times between devices, and no relationship between age and nebulization time for any of the devices tested.

The mean amount of salbutamol retained in each of the nebulizers after the output had ceased was 54.5 (SD 18.2)\% for the Acorn ${ }^{\circledR}, 55.7$ (SD 7.0)\% for the Acorn ${ }^{\circledR}$

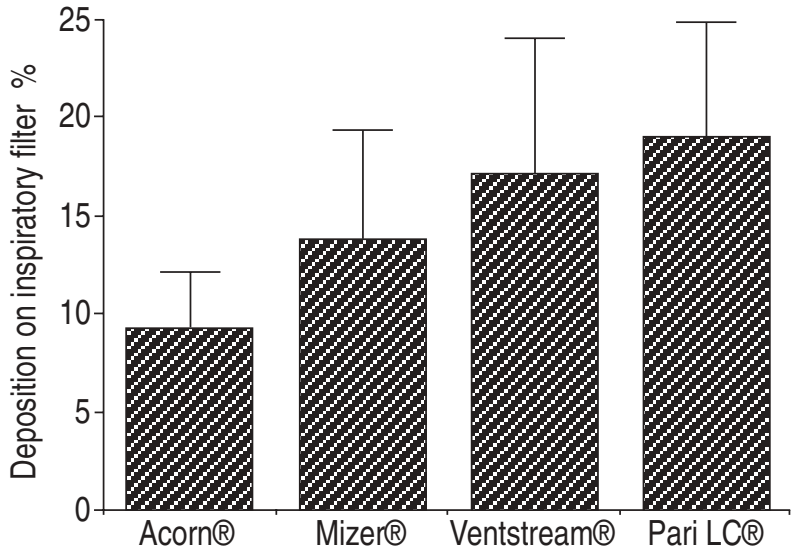

Fig. 3. - Mean (SD) delivery of nebulized salbutamol to inspiratory filters $(n=18)$ from four nebulization systems: Acorn ${ }^{\circ}$; Acorn ${ }^{\circledR}$ with Mizer ${ }^{\circledR}$; Ventstream ${ }^{\circledR}$ (all MedicAid, Pagham, UK); and Pari LC® (Pari, Germany).

and Mizer ${ }^{\circledR}, 56.3$ (SD 13.5)\% for the Ventstream ${ }^{\circledR}$ and 57.9 (SD 7.4)\% for the Pari®. There was no significant difference between nebulizers in the amount retained in the nebulizer bowl. The mean amount deposited in the Mizer® was 7.7 (SD 5.5)\%.

\section{Discussion}

Measurement of drug delivery using inspiratory filters is a noninvasive method of comparing the dose that may be inhaled from different devices when used by patients. The results of this study indicate that both storage chambers, such as the Mizer ${ }^{\circledR}$, and Venturi nebulizers, such as the Ventstream ${ }^{\circledR}$ and Pari ${ }^{\circledR}$, can increase the dose of drug inhaled by children as young as 3 yrs of age, and that the Venturi nebulizers appear to be the most efficient of the devices assessed. Previous studies in adults have produced similar results showing improved deposition from holding chambers [3, 12] and Venturi-type nebulizers [15] as compared with standard jet nebulizers. A study in children (aged 10-16 yrs) also demonstrated enhanced drug delivery when using holding chambers [13].

It must be noted that Venturi nebulizers are much more costly than "disposable" jet nebulizers such as the Acorn ${ }^{\circledR}$. Hence, the increase in drug delivery between the two types of nebulizers may not be solely due to the active entrainment principle utilized by the Venturi nebulizers, but may be partially attributed to the better quality of construction of these nebulizers. However, in a filter study using a breathing simulator, the output from Venturi nebulizers was found to be consistently higher than that from a good quality constant output jet nebulizer (Sidestream; MedicAid, Pagham, UK) [17, 18].

No change was found in the dose delivered to inspiratory filters with an increase in the subject's age, height or weight for any of the devices tested. Hence, the dose inhaled, when corrected for body weight, is greatest in the youngest patients. However, further work is required to assess differences in drug deposition in the lungs in children of different ages. Our current results also indicate that the intrasubject inhaled dose from all the devices is very variable, consistent with results from previous studies $[2-4,11-13,15]$. 
In our study, the mean deposition on the inspiratory filter when using the Acorn ${ }^{\circledR}$ was $9.4 \%$ of the nominal dose and this increased to $13.9 \%$ with the Mizer ${ }^{\circledR}$ chamber attached. A study in older children, using a 4 $\mathrm{mL}$ fill in an Acorn ${ }^{\circledR}$ nebulizer, found lung doses increased from 5.8 to $11.1 \%$ when the Mizer ${ }^{\circledR}$ chamber was attached [13], while a study in adults reported $14.3 \%$ deposition with the Mizer® using a $6 \mathrm{~mL}$ fill [3]. In the latter study, administration of drug took in excess of 30 min due to the large fill volume.

Studies utilizing inspiratory filters, such as the one presented here, are useful in providing a guide to the relative effectiveness of such devices. However, it is important to note that these are "inhaled" doses, and not the doses deposited in the lungs. Once inhaled, the aerosol may be deposited in the upper airways, the lower airways, or exhaled [19]. The pattern of deposition within the lungs is affected by factors such as the age and tidal volume of the patient, and the particle size distribution of the aerosol. Unfortunately, it is not yet possible to predict the dose depositing in the lungs from jet nebulizers, which produce polydisperse aerosols, purely from measurements of the dose inhaled and the particle size of the aerosolized drug, even for adults.

The two Venturi nebulizers delivered similar quantities of drug to the filter but the aerosols generated by these devices have different MMADs. The Ventstream ${ }^{\circledR}$, with the lower MMAD, could be expected to produce less upper airways deposition and hence a greater fraction of the inhaled dose should reach the smaller airways $[16,19]$, while a greater proportion of the particles generated by the Pari® nebulizer should deposit in the upper airways [19].

The central to peripheral deposition within the lungs could also be expected to be different for the two Venturi nebulizers. However, for most drugs, the optimal sites of action within the airways is still unknown, and may vary with different types of drugs. Hence, the significance of differences in the pattern of deposition within the lungs is unclear [9]. A recent pharmacokinetic study, using $2.5 \mathrm{~mL}$ of salbutamol, indicated that the dose delivered to the lungs by the Ventstream ${ }^{\circledR}$ was approximately twice that when using a conventional Hudson nebulizer [16]. A recent radiolabelled deposition study in adults using the Pari LC® found a mean lung deposition of $12.8 \%$, a figure greater than values generally reported for conventional nebulizers [2-4]. Chronic airways obstruction and bronchoconstriction, which can occur in patients with cystic fibrosis, will affect the pattern of deposition within the lungs, resulting in increased central and reduced peripheral deposition [9]. However, the patients recruited for this study were all clinically healthy, and those who could perform reliable spirometric manoeuvres had lung function parameters within the normal range, hence this is unlikely to greatly alter drug deposition in these individuals.

It is important to remember that different nebulizers have different output characteristics and that other standard nebulizers or other storage chambers may perform very differently. Furthermore, this study utilized salbutamol and it is possible that the nebulization times and outputs maybe different with more viscous solutions or when nebulizing suspensions. For instance, using the low-flow Pari® system, nebulization times may be significantly greater when using viscous solutions [11], while the lower particle size generated by the Ventstream ${ }^{\circledR}$ may result in a relative reduction in the output of suspensions such as steroid preparations [10].

\section{References}

1. Dolovich M. Physical principles underlying aerosol therapy. J Aerosol Med 1989; 2: 171-185.

2. Johnson MA, Newman SP, Bloom R, Talaee N, Clarke SW. Delivery of albuterol and ipatropium bromide from two nebuliser systems in chronic stable asthma: efficacy and pulmonary deposition. Chest 1991; 99: 1139-1144.

3. Thomas SHL, O'Doherty MJ, Page CJ, Nunan TO, Bateman NT. Which apparatus for inhaled pentamidine? A comparison of pulmonary deposition via eight nebulisers. Eur Respir J 1991; 4: 616-622.

4. Thomas SHL, O'Doherty MJ, Page CJ, Nunan TO. Variability in the measurement of nebulised aerosol deposition in man. Clin Sci 1991; 81: 767-775.

5. Chua HL, Collis GG, Newbury AM, et al. The influence of age on aerosol deposition in children with cystic fibrosis. Eur Respir J 1994; 7: 2185-2191.

6. Mukhopadhyay S, Staddon GE, Eastman C, Palmer M, Rhys Davies E, Carswell F. The quantitative distribution of nebulised antibiotic in the lungs in cystic fibrosis. Respir Med 1994; 88: 203-211.

7. Collis GG, Cole CH, Le Souëf PN. Dilution of nebulised aerosols by air entrainment in children. Lancet 1990; 336: 341-343.

8. Everard ML, Clark AR, Milner AD. Drug delivery from jet nebulisers. Arch Dis Child 1992; 67: 586-591.

9. Gonda I. Aerosols for delivery of therapeutic and diagnostic agents to the respiratory tract. Crit Rev Ther Drug Carrier Syst 1990; 6: 273-313.

10. Nikander K. Drug delivery systems. J Aerosol Med 1994; 7 (Suppl. 1): S19-24.

11. Newman SP, Pitcairn GR, Hooper G, Knoch M. Efficient drug delivery to the lungs from continuously operated open-vent nebuliser and low pressure compressor system. Eur Respir J 1994; 7: 1177-1181.

12. Thomas SHL, Langford JA, George RDG, Geddes DM. Improving the efficiency of drug administration with jet nebulisers. Lancet 1988; i: 126.

13. Marshall LM, Francis PW, Khafagi FA. Aerosol deposition in cystic fibrosis using an aerosol conservation device and a conventional jet nebulizer. J Paediatr Child Health 1994; 30: 65-67.

14. Mercer TT, Goddard RF, Flores RL. Effect of auxiliary air flow on the output characteristics of compressed-air nebulisers. Ann Allergy 1969; 27: 211-217.

15. Knoch M, Wunderlich E, Geldner S. A nebulizer system for highly reproducible aerosol delivery. J Aerosol Med 1994; 7: 229-237.

16. Newnham DM, Lipworth BJ. Nebuliser performance, pharmacokinetics, airways and systemic effects of salbutamol given via a novel nebuliser delivery system ("Ventstream"). Thorax 1994; 49: 762-770.

17. Dennis JH. Drug nebuliser design and performance: breath enhanced jet $v s$ constant output jet $v s$ ultrasonic. J Aerosol Med 1995; 8: 277-280.

18. Barry PW, O'Callaghan C. The output of budesonide from nebulisers. In: Drug Delivery to the Lungs 1995; VI: pp. 98-101.

19. Brain JB, Valberg PA. State of the art: deposition of aerosol in respiratory tract. Am Rev Respir Dis 1979; 120: 1325-1371. 